\title{
AUTOFICCIÓN, METAFICCIÓN Y ESPIRITUALIDAD EN MARIO LEVRERO
}

\begin{abstract}
Resumen. Se discuten algunos aspectos de la interrelación entre autoficcionalidad, metaficcionalidad y búsqueda de la espiritualidad en dos textos del escritor uruguayo Jorge Mario Varlotta Levrero (1940-2004), mejor conocido por su nombre literario: ‘Mario Levrero'. En estos escritos, de fuerte carácter autobiográfico y autorreflexivo, se advierte la necesidad de emprender un proceso de autodescubrimiento y autoanálisis, y también la urgencia de recuperar una espiritualidad en crisis. Para llevar a cabo ambas tareas, Levrero descarta pretensiones de profundidad y solemnidad, optando, en cambio, por la representación de lo (aparentemente) banal e insignificante.
\end{abstract}

Palabras clave: narrativa uruguaya, autobiografía, autoficción, metaficción, diario.

\section{Introducción}

La obra del escritor uruguayo Jorge Mario Varlotta Levrero (19402004), mejor conocido por su nombre literario, o su "yo literario", como él mismo lo llama: "Mario Levrero», ha ido acumulando, ya incluso poco antes de su muerte, un volumen apreciable, en calidad y cantidad, de estudios analíticos, amén de otros trabajos que reúnen numerosas entrevistas y conversaciones sobre distintos aspectos de una producción literaria tan fascinante como original, y que va ganando cada vez más intérpretes y lectores. Aunque el reconocimiento crítico de sus textos ya se venía produciendo cuando era un escritor relativamente poco conocido, de una vida itinerante entre Uruguay y Argentina, la acogida más entusiasta solo se produciría justo un año después de su fallecimiento, con la publicación de La novela luminosa (2005), quizá

\footnotetext{
* Uniwersytet im. Adama Mickiewicza w Poznaniu / Uniwersytet Łódzki.
} 
su texto de elaboración más ardua y prolongada, objeto durante años de numerosas interrupciones y modificaciones.

En este trabajo se propone una relectura de dos textos que complementan y completan a la célebre novela «luminosa»; se trata del Diario de un canalla, redactado entre diciembre de 1986 y enero de 1987, y El discurso vacío, de 1996. En estos escritos, pertenecientes a la etapa de madurez literaria de su autor, se ofrece una sugerente síntesis de elementos autobiográficos y ficcionales con otros de carácter autorreflexivo sobre la función y propósito de la creación literaria y artística en general. Las escrituras autoficcionales de Levrero asumen con preferencia la forma del diario al menos por dos razones de índole muy personal -que constituyen también elementos-guía de sus últimos años de producción literaria-. Por un lado, la necesidad de emprender un proceso subjetivo de autodescubrimiento y autoanálisis, $\mathrm{y}$, por otro, la urgencia de recuperar una espiritualidad en crisis. Lo interesante del caso Levrero es que, para llevar a cabo propósitos tan graves e incluso solemnes, el tipo elegido de discurso literario opta por descartar pretensiones de profundidad, eligiendo, en cambio, la representación -enriquecida con generosas dosis de humorde lo que resulta, en apariencia al menos, banal e intrascendente. Se cree que la puesta en escena de recursos autoficcionales y metaficcionales en la obra tardía de Levrero no representa una finalidad en sí misma, sino que es resultado de una toma de conciencia del autor acerca de las posibilidades espiritual y moralmente terapéuticas de la vocación artístico-literaria.

\section{Lo autoficcional y lo metaficcional en la escritura levreriana}

Si es cierto que una de las tendencias más destacadas en la literatura contemporánea de las últimas décadas es la proliferación de las «novelas del Yo»-según la expresión del crítico argentino Alberto Giordano-, entre las que se incluyen diversas modalidades narrativas de carácter autobiográfico y autoficcional, cabe preguntarse qué lugar ocupa en el presente una escritura como la de Levrero que muestra varias de las características asociadas con el auge literario posmoderno de (sobre)exposición del ego, pero también, y ante todo, qué la diferencia de otras variantes de la autoficción. Una primera aproximación a esta doble interrogante exige recordar que la vigorosa presencia de lo autoficcional en la obra más madura de Levrero resultó de un proceso gradual, que se fue gestando con lentitud, al margen de lo que llegaría a constituir 
una especie de moda literaria de las últimas tres décadas en el mundo hispánico.

En segundo término, más significativo, lo que diferencia a la autoficcionalidad levreriana de otras variedades es el carácter espiritualmente comprometido, dosificado a partes iguales de dramatismo y humor negro, que emana de sus últimos trabajos. Esto es algo que destaca, sobre todo, en los textos aquí considerados y que fueron agrupados -junto a La novela luminosa- por una intérprete y colaborada cercana del escritor uruguayo en una «trilogía luminosa», dado que presentan, aparte de su afán metadiegético, una unidad fundamentada «en la afinidad constructiva temática y formal, forjada con un propósito definido». Es que, según observa dicha autora, el estudio de los tres textos «luminosos» posibilitaría «la comprensión de la poética que Levrero enunció finalmente, la que pone en cuestión el problema de la verdad y la escrituración del sujeto» (Corbellini, 2011: 253).

En lo que sigue se pondrá el acento en ese dueto fundamental que define en gran medida, según se cree, la obra tardía de Mario Levrero: un proceso de autoanálisis (lo que el autor llama una «investigación de mí mismo»), y otro que busca la recuperación de cierto ámbito de espiritualidad. Pero el desarrollo del tema demanda tener siempre presente la interacción entre reflexiones autoficcionales y metaficcionales en que se apoya Mario Levrero para llevar a cabo dichas labores autoanalíticas y de recobramiento de lo espiritual.

Respecto de este último aspecto se puede coincidir con las palabras del crítico español Ignacio Echevarría (2017: 137-138), quien, refiriéndose al conjunto de escritos de Levrero, escribe que «la obsesión que recorre su obra» es «la búsqueda de la salvación del Espíritu»; pero que dicho «Espíritu» no es el del «'mundo moderno", sino, más humildemente, la personalidad excéntrica y escurridiza del propio Levrero». Sobre esta cita solo resta añadir que en los textos del autor uruguayo se muestra una preocupación por una espiritualidad en crisis también en un sentido más global, como claro síntoma de un malestar cultural en la época contemporánea.

Antes de comentar por separado cada uno de los dos textos levrerianos ya mencionados, hay que recordar que el término «autoficción» apunta, como ha escrito una intérprete, Marie Darrieussecq, a una narración «en primera persona, que se presenta como ficticia [...], pero en la que el autor aparece homodiegéticamente con su nombre propio y cuya verosimilitud se basa en múltiples 'efectos de vida'» (cit. en Souquet, 2014: 249). Para otro especialista, Vicent Colonna: «Una autoficción es una obra literaria por la cual un escritor se inventa una personalidad y una existencia, conservando 
su identidad real (su verdadero nombre)» (cit. en Alberca 2007: 151-152). No es casual que la presencia autoficcional aparezca entrelazada en obras que también ostentan un fuerte carácter metaficcional; el término 'metaficción' se refiere, según explica otra investigadora, «a la escritura ficcional que llama la atención, de manera autoconsciente y sistemática, sobre su condición de artefacto para plantear así cuestiones sobre la relación entre ficción y realidad» (Waugh, 1984: 2).

\subsection{Diario de un canalla}

El autor uruguayo combinó estrategias autoficcionales y metaficcionales en textos de una densa hibridez que desafían clasificaciones genéricas rígidas. En ellos se pueden hallar elementos de clara referencialidad autobiográfica fusionados con otros cercanos a una poética de lo fantástico u onírico. Pues, para comenzar, no hay que olvidar la advertencia que el propio Jorge Varlotta hace respecto de su alter ego autoral, Mario Levrero (2016a: 169), en el sentido de que, afirma, «siempre he tratado de dejar en claro que éste que escribe no soy exactamente yo». Asimismo, en su auto-entrevista de 1992, Levrero intenta clarificar la importancia, así como la ambigüedad, del componente autobiográfico en sus autoficciones: «Yo hablo de cosas vividas, pero en general no vividas en ese plano de la realidad con el que se construyen habitualmente las biografías» (cf. Gandolfo, 2013: 96). El Diario de un canalla es, en todo caso, el primer texto significativo de Levrero en el que su autor se ufana de ser y no ser él mismo el protagonista del discurso autoficcional.

A pesar de las advertencias del autor, es notable en el Diario la proliferación de detalles autobiográficos, toda vez que su objetivo declarado es activar de nuevo a la escritura, después de un tiempo considerable dedicado a faenas de mera supervivencia económica en Buenos Aires. Pero si el que pone las cosas por escrito no es exactamente el autor, ¿quién es entonces el que escribe -refiriéndose al proceso mismo de la escritura- estas palabras?: «Surgió entonces un texto, 'Diario de un canalla', que trata de cosas que me están sucediendo en el momento de escribirlas. Es absolutamente autobiográfico, sin sueños ni datos de invención. Son mis vivencias concretas» (cf. Gandolfo, 2013: 116). Se trata, en todo caso, de una ambigüedad característica de los textos autoficcionales, y en particular de las ficciones levrerianas.

Hay que tomar en cuenta que, en Diario de un canalla, Levrero refuerza una imagen bastante querida por él -que reaparece con frecuencia en sus 
escritos-. Se trata de una doble auto-representación de hombre derrotado por la vida, por un lado ${ }^{1}, \mathrm{y}$, por otro, de artista que, de modo más o menos heroico, se sobrepone a los golpes de una vida injusta y cruel. Primero escribe:

Estoy en esa etapa de la vida en que uno debe necesariamente volverse conservador; no queda mucha energía, no quedan muchas neuronas, no se puede contar, ya, con la súbita iluminación o con la pirueta salvadora. Muerto el espíritu, muerta toda chispa de fe, no se puede decir, creyéndola, 'Dios proveerá' (Levrero 2016a: 22).

Pero también más tarde, conforme relata las aventuras y desventuras del desvalido «Pajarito», el autor ve el esfuerzo del pequeño gorrión auspiciado por la voluntad del «Espíritu»-pues éste, escrito así, con mayúscula, sí que aún está vivo y coleando-. Pese a lo anterior, y aunque su trabajo adquiere entonces dimensiones casi prometeicas y renacen moderadas esperanzas tras la supervivencia casi milagrosa del gorrión, y aparecen aquí y allá destellos de optimismo, no hay que olvidar el horizonte de mortalidad y desilusión que se divisa siempre, más cerca o más lejos, en las ficciones del autor uruguayo. El Diario de un canalla se muestra como un texto particularmente instructivo de esta suerte de poética melancólica de su autor. Deja ver mucho del por qué y el cómo de su estructura y sus temas, pero también de qué manera el control sobre el discurso narrativo no es ni puede ser total, sobre todo en el caso de los trabajos tardíos de Levrero que suelen revelarse como resultados bastante distintos -incluso decepcionantes- de los originalmente concebidos.

En otro nivel, el Diario ofrece también un rostro jánico -pero en todo caso familiar a los lectores de Levrero-: por una parte, comienza como una confesión en la que el narrador se avergüenza de haber abandonado, por razones de estabilidad financiera, la redacción de su proyectada por mucho tiempo y nunca concluida «novela luminosa». Por otra parte, la suspensión de la escritura del texto original, es decir, la apología del autor de su cancelación se convierte en una nueva diégesis -orientada inicialmente por las peripecias del ave «Pajarito»- que ocupa 'por casualidad' el lugar del

${ }^{1}$ Sobre este primer aspecto hay que decir que Levrero no representa, desde luego, un caso aislado. Respecto de la autoimagen de escritor derrotado, pobre y casi fracasado que sobresale en varias obras autoficionales levrerianas, valen también los comentarios que Julio Premat hace en torno a las figuras autorales producidas por diversos literatos argentinos del siglo XX. Estos artistas buscan inscribirse «dentro de una tradición, renovada pero reconocible, de la melancolía occidental»; conforme a ella, el autor que desea ocupar un lugar en la historia de la literatura debe primero anularse como figura relevante. Es decir, según Premat (2009: 14-15), se trataría no solo de «narrar la aventura de la escritura [sino también de] inventar al responsable de lo que se lee, o sea al cabizbajo héroe de esa aventura». 
proyecto original. La historia del gorrión atrapado en el apartamento del protagonista es aquello que se da 'en lugar de lo otro', 'algo en vez de nada', 'lo mejor que se puede hacer bajo las circunstancias', etc.

El Diario de un canalla constituye, además, por un lado, una admisión de mea culpa -dado que su autor habría traicionado el arte, lo espiritual, por el negocio, lo material- que usurpa el relato incompleto de las experiencias luminosas. Por otro, el texto configura también una ficción por derecho propio, aunque surja -cosa característica de varios textos de Levrero- casi a pesar suyo. O sea, se trata de una novela que brota, poco más o menos por accidente, desde el interior de un diario 'no ficcional':

Por una serie de aparentes azares, he aquí que hoy me permito llegar a la conclusión de que este texto comienza a estructurarse, incluso he pensado un título: 'Diario de un canalla'. Porque los aparentes azares han determinado que hoy comenzara a pensar en esto como un diario (Levrero 2016a: 25).

Al final, el texto resultante del Diario revela en la voluntad del artista una doble aspiración de triunfo: por auto-conocerse y también por conectarse con la espiritualidad inherente a ciertos eventos cotidianos; en ambos casos la diégesis se satura de reflexiones sobre sus propias condiciones y modos de estructuración. En ocasiones, la victoria se obtiene, siquiera a medias, cuando, por ejemplo, en medio de la lucha del autor-narrador-protagonista sobre la bestia negra de los últimos escritos levrerianos, a saber, el conjunto de pequeños y grandes malestares corporales y contratiempos cotidianos, el narrador discierne algún tipo de revelación casi mística, en las que se entrevé -como en todos los episodios relativos a la casi épica supervivencia del gorrión «Pajarito»- la presencia de las experiencias luminosas, o del todo del «Espíritu».

Se da una presencia constante en la obra del escritor uruguayo de ideas de triunfo y fracaso personal. Esto parece ser una consecuencia del asumirse el propio autor, Mario Levrero, como centro irradiador absoluto del texto. En esto tiene razón un intérprete, cuando indica, a propósito del Diario de un canalla, que: «El diario se escribe sin casi salir de su casa. El narrador-personaje se postula como un dios que observa y registra todo lo que sucede en su entorno, practicando una estética minimalista donde aparentemente nada sucede» (Olivera, 2010: 342). En su modalidad de 'motor inmóvil', Levrero puede aparecer dentro y fuera del texto; a veces, las menos, como un simple extra que apenas participa en la (mínima) acción de sus ficciones, en otras, las más, como auténtico deus ex machina de su cosmos literario.

Si la fijación en el proceso de construcción de un texto sobresale como una de las características definitorias de una buena parte de la llamada 
literatura posmoderna, entonces la literatura autoficcional y metaficcional levreriana coincide con algunos de sus rasgos básicos. El más significativo en su caso es la autoreferencialidad del relato que incluye a la propia figura del narrador. Como lo explica un intérprete: «Levrero referencializa el discurso en el sujeto de la acción; este es correferencial con el sujeto de la enunciación. Esta es una de las características de los diarios de la última época. La referencia del relato es el propio relato y el propio sujeto de la enunciación que coexiste con los hechos que narra o describe» (Olivera, 2010: 343). En su Diario, Levrero toma distancia y reflexiona metaficcionalmente tanto sobre el tipo de texto que está elaborando, como sobre cómo podría éste contribuir a su propia rehabilitación espiritual.

\subsection{El discurso vacío}

Mario Levrero explota al máximo en esta obra tanto las posibilidades de la escritura semi-diarista y autoficcional que ya introdujera en su diario-novela anterior, como la extrañeza de los lectores ante su sugestivo título. Si en su forma más tradicional el diario aparece como una escritura de la subjetividad, la expresión de un diálogo privadísimo de un escritor o escritora con su yo, en tiempos más recientes esa conversación privada se hace pública, y acaba compartiéndose con lectores ansiosos por conocer los detalles incluso más íntimos de la vida de su autor o autora predilectos.

Puesto que la pesquisa levreriana de la espiritualidad no está exenta, como ya se indicó, de humor e ironía, luego sus diarios o semi-diarios ficcionales, como El discurso vacío, no se privan de mofarse de ciertas expectativas tanto de una lectura 'profunda' como de una más bien 'frívola' de los eventos relatados. Pero tampoco renuncian, cuando es menester, al tono grave y hasta solemne. De hecho, el plan inicial del libro no se destaca precisamente por su carácter lúdico. El autor-narrador se propone ser consecuente con lo que él denomina una estricta «terapia grafológica» que consiste en mejorar el carácter como resultado de un progreso en la habilidad caligráfica. Según confiesa, este método le habría sido «sugerido por un amigo loco»; se trata de un método que parte, nada menos, «del presupuesto conductista de que los cambios de la conducta pueden producir cambios a nivel psíquico. Cambiando pues la conducta observada en la escritura se piensa que podría llegarse a cambiar otras cosas en una persona» (Levrero, 2016b: 15).

La voz narradora de El discurso vacío afirma no interesarle el contenido de lo escrito; no es (no sería) importante de qué trata el relato, 
sino tan solo la apariencia en el trazado de las letras. El autor declara que, cuanto menos interesante sea lo escrito, mejores serán los resultados caligráficos. Escribe Levrero (2016b: 34): «Hoy voy a tratar de eludir temas interesantes para tratar de progresar en el trazado de las letras». Cuanto menos se inmiscuya la 'literatura' (bajo la tentación de un relato o una narración cautivantes) mejores los resultados para la personalidad de la voz narrativa. De nuevo el propio autor: «¿Qué puedo escribir, que no sea demasiado interesante como para que me distraiga de mi propósito, y al mismo tiempo no me resulte tan aburrido que deje el trabajo a medio hacer, entre grandes bostezos?» (Levrero, 2016b: 34).

La meta que se autoimpone el autor uruguayo se expresa con claridad en este otro fragmento: «Debo caligrafiar. De eso se trata. Debo permitir que mi yo se agrande por el mágico influjo de la grafología. Letra grande, yo grande. Letra chica, yo chico. Letra linda, yo lindo» (Levrero, 2016b: 36). No obstante, las cosas no son tan sencillas. Antes que nada, hay que tener en cuenta que $E l$ discurso vacío ahonda las reflexiones metaficcionales presentes en el anterior Diario de un canalla. Este segundo texto se ofrece como un dispositivo conscientemente construido para un propósito bien concreto, aunque de sabor un tanto anacrónico en su (aparente) ingenuidad; es decir, de nuevo: el autor-narrador se propone mejorar, así, de forma casi mecánica, su carácter o personalidad, en definitiva, su espíritu, mediante el perfeccionamiento de la caligrafía personal.

Se trataría en principio de una finalidad 'no literaria' que, no obstante, poco a poco se irá contaminando, en forma supuestamente involuntaria, de 'literatura'. Pero los lectores nos percatamos muy pronto que el discurso semi-autobiográfico de Levrero no es ni vacío ni de carácter puramente técnico. En realidad, El discurso vacío está bastante lleno, contiene una plétora de eventos, anodinos y banales que resultan típicos del mundo autoficcional levreriano. Es decir, son distintivos en el sentido de que su interés reside precisamente en su carácter in-interesante, pero que, por eso mismo, ofrecen pistas para el (posible) encuentro con elevados ámbitos espirituales. Pero dicho encuentro no se puede forzar, al narrador solo le queda aguardar, atento, su repentina manifestación. Considérese el siguiente ejemplo. Se trata de una breve anotación fechada «15 de diciembre»:

Y así van las cosas. No sé qué más puedo decir. Así van las cosas. (Me viene a la mente el título de una novela de Saul Bellow: Hombre en suspenso. Yo también estoy en una especie de suspenso, no colgando sin que mis pies toquen el piso, sino más bien en el sentido de 'puntos suspensivos'. Pausa, demora, quedarse en la última sílaba de la última palabra, como arrastrándola [...] (2016b: 86). 
La plenitud del texto 'vacío' de Levrero es consecuencia, simple y llanamente, de la imposibilidad de la vaciedad narrativa, del sinsentido de una narración que no narre 'algo', y que no luche contra la amenaza de esa nada que (nos) llama (que llamaba al autor en esa época) desde la muerte. Como ha escrito con acierto un intérprete del texto, «toda escritura es un intento de comunicar, aunque se proponga como vacía. El escritor no puede renunciar a la lucidez ni al conocimiento del oficio, y lo que parece un fracaso [es decir, la no consecución de una caligrafía bella, A.R.R.] es a la vez un éxito que le da sentido al libro» (Ricciardi, 2014: 155). O, con las palabras del propio Mario Levrero:

Tengo plena conciencia de que estos ejercicios caligráficos han ido derivando en ejercicios narrativos; hay un discurso - un estilo, una forma más que un pensamientoque se impone ansiosamente a mi voluntad (2016b: 45).

Y, sin embargo, el (sub)producto 'literario' de esa narración que se impone, como él dice, a su pesar, refleja de modo íntegro su personalidad. Así como en sus reflexiones metaficcionales el autor insiste en el carácter impremeditado del relato, es decir, en el nacimiento fortuito de una narración desde un gesto creativo de absoluta libertad, así parece creer que la adquisición de experiencias luminosas, saturadas de espiritualidad, se obtendrían, si acaso, también por casualidad, hasta por una suerte de estado místico, gracias a una súbita iluminación.

\section{Conclusiones}

La estructura diarista de los dos textos levrerianos aquí comentados se emplaza entre los planos - en apariencia, contrapuestos- de la banalidad y la trascendencia, convocados los dos a la mirada siempre curiosa de los lectores. Pero estos mismos lectores, ávidos tanto de detalles personales sobre el autor como de asistir -figuradamente- al desvelamiento de las «experiencias luminosas», se ven expuestos casi siempre a una experiencia frustrante por el predominio de la digresión y la incompletitud narrativa. El diario ficcional o ficción diarista de Levrero es un dispositivo truncado y fragmentario como los propios eventos que conforman el marco de vida del narrador-personaje. Conviene ahora resaltar la presencia en la obra tardía de Levrero -representada en el Diario de un canalla y El discurso vacíode los dos aspectos característicos indicados al comienzo de este trabajo.

Por un lado, es notable el esfuerzo de autoanálisis que realiza el autor-protagonista. Se trata de un sujeto máximamente auto-reflexivo 
que se complace en examinarse en cada situación cotidiana. Es un autor en estado permanente de alerta autocrítica. El anhelo sincero del escritor de perfeccionarse moral y espiritualmente, de ser 'un hombre mejor', lo lleva a una especie de hipercriticismo extremo de su ser social. En este punto, el autor-protagonista parece incluso disfrutar de su tarea de autodenigración y rebajamiento implacable de la autoestima ${ }^{2}$. En todo caso, la actitud (hiper)autocrítica de Levrero está orientada en principio por metas tan elevadas que al final, de manera más bien paradójica y trágica, ella misma tiende a distanciarlo de ese ámbito cotidiano de espontaneidad y naturalidad afectiva del que se siente mayormente desvinculado, y con el que añora formar parte de un modo más cálido y pleno.

Por otro lado, los medios autoficcionales y metaficcionales que Levrero utiliza para acometer su magna tarea de auto-reforma moral y espiritual, parecen conducirlo, de un modo nuevamente (en apariencia) paradójico a concentrase en la observación y descripción minuciosa -en ocasiones fronteriza con lo exasperante- no de eventos con cierta aura de sublimidad o trascendencia, sino en otros que, protagonizados sobre todo por animales (perros, palomas, gorriones, por ejemplo) parecerían alejar al narrador del acceso a altos planos de perfección espiritual. Ahora bien, lo interesante del caso Levrero, es que es justamente en esa dimensión tan particular, constituida por la contemplación meditada de eventos marginales, donde sus diversos alter ego literarios hallan las claves para un remozamiento de sus desgastadas energías espirituales. En realidad, cuanto más se esfuerzan las maltrechas figuras de autor levrerianas por elevar sus ambiciones espirituales y morales, tanto más deben apoyarse en el terreno de la pura y dura cotidianeidad.

\section{Bibliografía}

ALBERCA, M. (2007). El pacto ambiguo. De la novela autobiográfica a la autoficción. Madrid: Biblioteca Nueva.

CORBELLINI, H. (2011). «La trilogía luminosa de Mario Levrero», Revista de la Biblioteca Nacional, 3/4-5, 251-262 [en línea] <http://www.bibna.gub.uy/innovaportal/file/10824/1/revista_7_6_11_web.pdf $>$, fecha de consulta: 23 de abril de 2018.

${ }^{2}$ Recuérdese lo indicado en la primera nota, apoyada en la interpretación de J. Premat, a propósito de las figuras de autor que giran en torno a una «autorepresentación negativa»-según la expresión de I. Lucía en su reseña del libro de Premat, en Orbis Tertius, 2010, 15 (16), <https://www.orbistertius.unlp.edu.ar/article/view/OTv15n16r15/pdf_477>. 
ECHEVARRÍA, I. (2017). «Levrero y los pájaros», en P. SILVA OLAZÁBAL (ed.), Conversaciones con Mario Levrero. Valencia: Ediciones Contrabando, 137-147.

GANDOLFO, E. (comp.) (2013). Mario Levrero. Un silencio menos. Conversaciones compiladas por Elvio E. Gandolfo. Buenos Aires: Mansalva.

HUTCHEON, L. (2013). Narcissistic Narrative. The Metafictional Paradox. Toronto: Wilfrid Laurier University Press.

LEVRERO, M. (2016a). Diario de un canalla. Burdeos 1972. Barcelona: Random House, segunda edición.

LEVRERO, M. (2016b). El discurso vacío. Barcelona: Debolsillo.

LUCÍA, I. (2010). «Reseña de Julio Premat, Héroes sin atributos: figuras de autor en la literatura argentina. Buenos Aires, Fondo de Cultura Económica, 2009, Colección 'Tierra Firme', 276 páginas», Orbis Tertius, 15 (16) [en línea] <https:// www.orbistertius.unlp.edu.ar/article/view/OTv15n16r15/pdf_477>, fecha de consulta: 4 de agosto de 2019.

OLIVERA, J. (2010). «Mario Levrero en sus diarios: de la ficción a la biografía», Anales de Literatura Hispanoamericana, 39, 331-347 [en línea] <https://core. ac.uk/download/pdf/38824517.pdf $>$, fecha de consulta: 1 de agosto de 2018.

PREMAT, J. (2009). Héroes sin atributos. Figuras de autor en la literatura argentina. Buenos Aires: FCE.

RICCIARDI, C. (2014). «Los (re)pliegues del discurso (vacío)», en G. FRANCO et al. (eds.), Caza de Levrero. Asedios críticos a la obra de Mario Levrero. Montevideo: Rebeca Linke Editoras, 147-157.

SOUQUET, L. (2014). «Una autoficción 'espectacular': Pedro Lemebel y Fernando Vallejo», en A. CASAS (ed.), El yo fabulado. Nuevas aproximaciones críticas a la autoficción. Madrid: Iberoamericana-Vervuert, 247-267.

WAUGH, P. (1984). Metafiction. The Theory and Practice of Self-Conscious Fiction. London and New York: Routledge. 